\title{
HUBUNGAN KOORDINAS MATA TANGAN TERHADAP KETERAMPILAN PASSING ATAS SISWA SMP NEGERI 1 LEBONG UTARA KABUPATEN LEBONG
}

\author{
Feby Elra Perdima, M.Pd \\ Correspondence: Universitas Dehasen Bengkulu, Bengkulu, Indonesia \\ E-mail: perdima.elra@gmail.com
}

\begin{abstract}
Based on the observation in the field it shows that still lack of agility of ability eyes and hands coordination to passing skill student at SMP N 1 Lebong. This study aims to explain the relationship of eyes and hands coordination to the passing skill student at SMP N 1 Lebong. This research method used is correlation, with the population of this study a number of 17 athletes and samples taken by using the total sampling technique so that obtained a sample of 17 athletes. Eyes and hands coordination test and passing skill used product moment. The result of analysis shows that there is relationship between eyes and hands coordination to the passing skill is 0.78 .
\end{abstract}

Kata Kunci: Eyes, Hands Coordination, Passing Skill

\section{Pendahuluan}

Pendidikan jasmani, Olahraga dan Kesehatan (Penjasorkes) merupakan bagian dari pendidikan keseluruhannya dalam proses pembelajarannya mengutamakan aktivitas jasmani dan kebiasaan hidup sehat, menuju pertumbuhan dan perkembangan jasmani, mental, sosial, dan emosional yang selaras, serasi dan seimbang sesuai dengan perkembangan pendidikan nasional. Penjasorkes merupakan bagian integral dari sistem pendidikan dengan aktivitas jasmani sebagai media pendidikan. Namun demikian, bukan berarti pendidikan jasmani merupakan pendidikan yang hanya bertujuan untuk mengembangkan kemampuan jasmani anak, melainkan melalui aktivitas jasmani secara umum dapat dikembangkan pula potensi kognitif, afektif dan psikomotor siswa. Pendidikan jasmani dan kesehatan sebagai sarana pembentukan jasmani manusia, maka di sekolah-sekolah melalui mata pelajaran pendidikan jasmani diajarkan bermacammacam olahraga yang sesuai dengan tingkat pertumbuhan dan perkembangan anak. Dari sekian banyak cabang olahraga yang dikembangkan di sekolah saat ini, salah satunya yang mendapatkan perhatian dan pembinaan adalah olahraga bolavoli.

Menurut informasi dari guru pendidikan jasmani SMP Negeri 1 Lebong Utara Kabupaten Lebong dan pengamatan peneliti, para siswa belum dapat menguasai teknik dasar permainan bolavoli yang baik. Kekurangan keterampilan itu dapat dilihat melalui kemampuan siswa pada waktu melakukan Passing atas, yaitu: (a) sikap tangan dan jari yang salah (jari-jari tidak terbuka dengan lebar), (b) sikap lengan dan kaki salah, (c) bola di passing terlalu rendah, (d) bola ditarik atau dibawa terlalu jauh sehingga banyak terjadi kesalahan dalam siswa dalam

PJKR_

http://jurnal.unimed.ac.id/2012/index.php/jpehr/index 
melakukan passing atas. Dalam permainan bolavoli salah satu kesulitan yang dialami siswa adalah penguasaan teknik dasar, khususnya dalam keterampilan passing. teknik dasar inilah yang penting dikuasai karena teknik ini suatu teknik yang di gunakan untuk melakukan opperan kepada pemain smah untuk mendapatkan poin, selain itu teknik passing ini sering di gunakan dalam permainan bola voli dan juga teknik ini berfungsi untuk menerima service dari lawan. Untuk melakukan passing dibutuhkan ketangkasan, gerakan yang cepat, koordinasi mata, dibutuhkan koordinasi mata dan tangan yang baik. Oleh karena itu peneliti melakukan penelitian mengenai hubungan koordinasi mata tangan terhadap keterampilan passing atas siswa SMP Negeri 1 Lebong Utara Kabupaten Lebong.

Permainan bolavoli merupakan salah satu cabang olahraga yang membutuhkan keterampilan yang baik, olahraga ini tidak asing lagi bagi masyarakat Indonesia baik yang bertempat tinggal dikota maupun di pedesaan, permainan ini tidak mengenal usia, lapisan sosial masyarakat, dari orang dewasa maupun remaja bahkan sampai pada anak usia sekolah dasar. Adapun Permainan bolavoli merupakan salah satu jenis olahraga permainan yang dimainkan oleh dua regu secara berhadapan. Setiap regu terdiri atas enam orang pemain, permainan ini dilakukan dilapangan yang berbentuk persegi panjang. Permainan bolavoli merupakan suatu permainan yang kompleks yang tidak mudah dilakukan oleh setiap orang. Sebab, dalam permainan bolavoli dibutuhkan koordinasi gerak yang benar - benar bisa diandalkan untuk melakukan semua gerakan yang ada dalam permainan bolavoli. Ahmadi, Nuril, (2007). Pengertian lain yang di kemukakan oleh Machfud Irsyada dalam Berahun (2010) bahwa permainan bolavoli adalah: "Olahraga beregu, setiap regu berada pada petak lapangan permainan dan masingmasing dengan dibatasi oleh net, bola dimainkan dengan atau kedua tangan hilir mudik atau bolak balik melalui atas net secara teratur sampai bola menyentuh lantai atau mati di petak lawan dan mempertahankan agar bola tidak mati di petak sasaran permainan sendiri".

Permainan bolavoli passing atas memiliki peran dalam mengumpan bola kepada spiker, bila dibandingkan dengan passing bawah, passing atas lebih efektif dalam memberikan umpan kepada spiker. Agus Mukhloid (2010) Passing adalah usaha seorang pemain bola voli dengan menggunakan teknik tertentu untuk mengoperkan bola yang dimainkan kepada teman seregunya. Passing dapat dilakukan dengan dua tangan dan satu tangan, passing juga dapat dilakukan dari atas (passing atas) dan dari bawah (passing bawah). Menurut Mariyanto (1995) passing dalam permainan bolavoli adalah usaha ataupun upaya seorang pemain dengan cara menggunakan suatu teknik tertentu yang tujuannya adalah untuk memperoleh bola kepada lawan secepatnya untuk dimainkan didaerah sendiri. Dalam bukunya Yunus (1992) mengungkapkan pelaksanaan teknik passing atas secara normal adalah sebagai berikut:

a) Sikap permulaan, Ambil posisi sikap siap normal yaitu: kedua kaki berdiri selebar dada, berat badan menumpu pada kaki bagian depan, lutut ditekuk dengan badan merendah, tempatkan badan secepat mungkin di bawah bola, dengan kedua tangan di angkat lebih tinggi dari

PJKR_

http://jurnal.unimed.ac.id/2012/index.php/jpehr/index 
dahi dan jari-jari tangan terbuka lebar membentuk cekungan seperti setengah lingkaran bola.

b) Gerakan pelaksanaan, Tepat bola berada di atas dan sedikit di depan dahi, lengan diluruskan dengan gerakan agak eksplosif untuk mendorong bola. Perkenaan bola pada permukaan jari-jari ruas pertama dan kedua, dan yang dominan mendorong bola adalah ibu jari, jari telunjuk dan jari tengah. Pada waktu perkenaan dengan bola, jari-jari agak ditegangkan, kemudian diikuti dengan gerakan pergelangan tangan agar bola dapat memantul dengan baik.

c) Gerak lanjutan, Setelah bola memantul dengan baik, lanjutkan dengan meluruskan lengan kedepan atas sebagai suatu gerakan lanjutan, diikuti dengan memindahkan berat badan ke depan dengan melangkahkan kaki belakang ke depan dan segera mengambil sikap siap dalam posisi normal kembali.Urutan gerak passing atas atas dapat dilihat pada gambar di bawah ini:

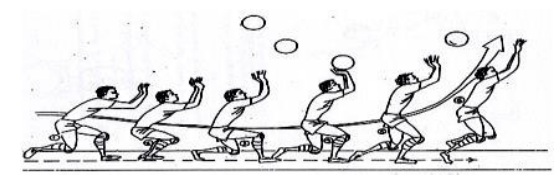

Gambar 1. Urutan Gerak Passing Atas, Y unus (1992)

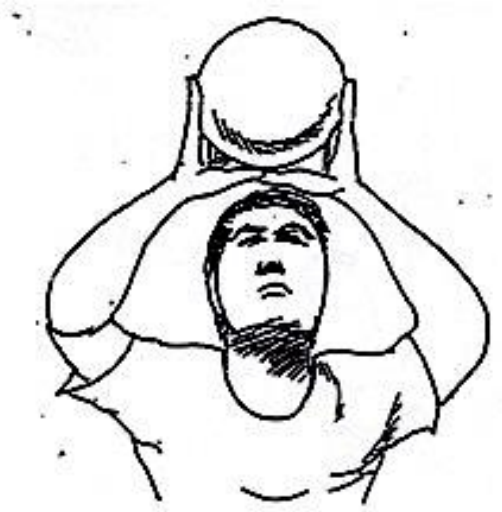

Gambar 2. Bentuk Tangan Saat Kontak dengan Bola, Yunus (1992)

Sama halnya dalam melakukan passing bawah, posisi dan jarak bola dengan badan tidak selalu dalam keadaan yang ideal untuk melakukan passing atas dengan posisi normal. Dalam Yunus (1992) dari situasi bola yang bermacammacam passing atas dapat dibagi sebagai berikut:

a) Passing atas pada bola rendah

b) Passing atas dengan bola disamping badan

c) Passing atas dengan bergeser mundur

d) Passing atas dengan bergerak mundur diagonal 45 derajat

e) Passing atas dengan meloncat

f) Passing atas kebelakang 


\section{g) Passing atas kebelakang dengan berputar 180 derajat}

Dengan demikian keterampilan dalam bermain bolavoli yang baik dan benar, maka bola akan sulit untuk mati di dalam daerah sendiri dan bola akan mudah dimatikan di daerah lawan. Karena pada prinsipnya passing bawah tidak hanya digunakan untuk mengumpan bola kearah teman akan tetapi dapat digunakan sebagai pertahanan (driggling). Kemampuan passing bawah yang baik dapat dengan mudah mengantisipasi serangan dari daerah lawan baik itu berupa servis atas atau pukulan spike yang laju bolanya sangat cepat dan tajam menusuk ke daerah sendiri. Dengan demikian, skor lawan dalam permainan tidak dapat bertambah. Dengan adanya kemampuan servis dan smash yang baik akan memudahkan dalam mematikan bola di daerah lawan.

Menurut Jonath dan krampel dalam syafrudidin (1992) koordinasi merupakan kerjasama sistem persyarafan pusat sebagai sistem yang telah diselenggrakan oleh proses rangsangan dan hambatan serta otot rangak pada waktu jalanya suatu gerakan secara rerarah. Sedangkan menurut Suharno HP (1981), koordinasi adalah kemampuan untuk merangkaikan beberapa gerakan untuk mencapai suatu gerakan yang selaras sesuai dengan tujuan

\section{Metode}

Penelitian korelasi atau korelasional adalah suatu penelitian untuk mengetahui hubungan dan tingkat hubungan antara dua variabel diataranya variabel bebas dan terikat dimana bebas ialah koordinasi mata tangan sedangkan terikat passing atas bolavoli atau lebih tanpa ada upaya untuk mempengaruhi variabel tersebut sehingga tidak terdapat manipulasi variable, Faenkel dan Wallen (2008). Adanya hubungan dan tingkat variabel ini penting karena dengan mengetahui tingkat hubungan yang ada, peneliti akan dapat mengembangkannya sesuai dengan tujuan penelitian. Jenis penelitian ini biasanya melibatkan ukuran statistik/tingkat hubungan yang disebut dengan korelasi. Penelitian ini dimaksudkan untuk mengetahui hubungan koordinasi mata tangan terhadap passing atas siswa SMP Negeri 1 Lebong Utara dengan sampel 20 siswa.

\section{Pembahasan}

Seberapa besar Hubungan antara koordinasi mata tangan dengan keterampilan Passing Atas Bola Voli siswa SMP Negeri 1 Lebong Utara Kabupaten Lebong.

Analisis korelasi terhadap koordinasi mata tangan dengan keterampilan passing atas menghasilkan koefisien korelasi sebesar $\mathrm{rx}_{\mathrm{y} 1}=0,88$, Untuk lebih jelasnya dapat dilihat rangkuman hasil analisis.

Tabel 7. Rangkuman Hasil Analisis Korelasi antara Variabel Koordinas Mata Tangan (X1) dan Keterampilan Passing Atas (Y)

\begin{tabular}{llll}
\hline Korelasi & Koefisien Korelasi $\mathbf{r}$ & $\mathbf{r}$ Tabel & Keterangan \\
\hline X dan Y & $\mathbf{0 . 7 8}$ & $\mathbf{0 . 4 6 8}$ & Signifikan \\
\hline
\end{tabular}


Berdasarkan uji keberartian korelasi antara pasangan skor koordinasi mata tangan (X) dengan keterampilan Passing Atas (Y) sebagaimana terlihat pada Tabel 6 di atas diperoleh $t_{\text {hitung }}=0.78>r_{\text {tabel }}=0.468$ pada taraf signifikansi $\alpha \square=$ 0,05. Dengan demikian, $\mathrm{H}_{\mathrm{a}}$ yang mengatakan Terdapat hubungan yang signifikan antara koordinasi mata tangan terhadap keterampilan passing atas diterima, konsekuensinya $\mathrm{H}_{0}$ ditolak.. Selanjutnya untuk menentukan besarnya hubungan koordinasi mata tangan terhadap keterampilan passing atas ditunjukkan dari hasil analisis koefisien determinasinya yaitu sebesar 0,78 .

Penelitian ini bertujuan untuk mengetahui hubungan koordinasi mata tangan terhadap keterampilan passing atas bolavoli pada siswa SMP Negeri 1 Lebong Utara". Berdasarkan hasil penelitian menunjukkan bahwa ada hubungan yang signifikan antara koordinasi mata tangan dengan kemampuan passing atas pada siswa SMP Negeri 1 Lebong Utara". dengan nilai rx.y $=0,78>r(0.05)(16)=$ 0,468 . Koordinasi adalah kemampuan seseorang dalam merangkai berbagai gerakan menjadi satu dalam satu satuan waktu dengan gerakan yang selaras dan sesuai dengan tujuan, artinya tujuan dalam melakukan passing atas dengan tepat ke dalam sasaran nilai yang telah ditentukan.

Adanya sumbangan antara koordinasi mata-tangan dengan kemampuan passing atas karena koordinasi mata-tangan sangat diperlukan di dalam melakukan passing atas. Koordinasi mata-tangan dalam melakukan passing atas terutama pada saat melakukan gerakan melambungkan bola. Ketika melakukan lambungan passing atas, yaitu saat mengangkat lengan maka koordinasi matatangan sangat menentukan keberhasilan siswa dalam melakukan lambungan passing atas. Semakin baik koordinasi mata-tangan dan semakin singkat siswa dalam melakukan lambungan passing atas, maka akan diperoleh hasil lambungan passing atas yang optimal.

Jadi koordinasi mata-tangan sangat dibutuhkan dalam melakukan lambungan passing atas, khususnya ketepatan passing atas, karena koordinasi mata-tangan sangat dibutuhkan oleh siswa dalam mengarahkan suatu benda menuju sasaran yang akan dicapai, sehingga dengan koordinasi mata-tangan yang baik, maka persentase keberhasilan dalam melakukan passing atas agar tepat mengarah kepada sasaran akan semakin tinggi. Dengan koordinasi yang baik, maka suatu benda yang dilemparkan akan, berhasil menuju sasaran dengan baik.

Gerakan dalam tes koordinasi mata tangan juga sesuai atau bahkan sama dengan gerakan pada saat melakukan passing atas. Jadi koordinasi mata-tangan sangat dibutuhkan dalam melakukan lambungan passing atas, karena koordinasi mata-tangan sangat dibutuhkan oleh siswa dalam mengarahkan suatu benda menuju sasaran yang akan dicapai, sehingga dengan koordinasi mata-tangan yang baik, maka persentase keberhasilan dalam melakukan passing akan semakin 
tinggi. Dengan koordinasi yang baik, maka suatu benda yang dilemparkan akan berhasil menuju sasaran.

\section{Simpulan}

Berdasarkan analisis data dan pembahasan yang telah dipaparkan terdahulu, maka dapat dikemukakan beberapa kesimpulan sebagai berikut: Adanya hubungan yang signifikan antara koorinasi mata tangan terhadap keterampilan passing atas siswa SMP Negeri 1 Lebong Utara Kabupaten Lebong Provinsi Bengkulu sebesar 0.78.

\section{Rujukan}

Agus Mukhlaid, 2010. Pengertian passing dalam permainan bolavoli. Jakarta: Universitas Terbuka

Ahmadi, Nuril, 2007. Panduan Olahraga Bola Voli. Surakarta: Era PustakaUtama Faenkel dan Wallen, 2008. Pengertian korelasi. Jakarta: Universitas Terbuka Machfud Irsyad, 2010. Permainan Bola Voli Dasar. Jakarta: Universitas Terbuka Martyanto, 1995. Pengertian permainan passing atas bola voli: Universitas Terbuka

Suharno, 1981. Koordinasi Mata Tangan. Jakarta: Universitas Terbuka Syafiruddin,1992. Koordinasi Mata Tangan. Jakarta: Universitas Terbuka Yunus, M, 1992. Olahraga Pilihan Bolavoli. Jakarta: Departemen Pendidikan Direktorat Jendral Pendidikan Tinggi Proyek Pembinaan Tenaga Kependidikan 